\title{
Effects of digestive infusions of volatile fatty acids or glucose on food intake in lactating or dry cows
}

\author{
P Faverdin, B Richou, JL Peyraud \\ INRA, Station de Recherches sur la Vache Laitière, \\ Saint-Gilles, 35590 L'Hermitage, France
}

Many experiments have shown that different nutrients could act as satiety signals in the control of food intake, but little is known about their relative importance and variation in sensitivity of the animal according to its physiological status (Faverdin, 1990).

Isoenergetic amounts (20.3.MJ/d) of a volatile fatty acid (VFA) mixture (acetic/propionic/butyric acids, $10.8 / 3.57 / 2.55 \mathrm{~mol} / \mathrm{d}$ ) or glucose $(7.2 \mathrm{~mol} / \mathrm{d})$ were continuously infused respectively in the rumen and in the duodenuin of 3 lactating ( $30 \mathrm{~kg}$ of milk/d) and 3 non pregnant dry dairy cows. The effect of each energetic infusion was studied using a reversal design (control-energy-control) over 3 periods of $2 \mathrm{wk}$. The saline $(\mathrm{NaCl}$, $\mathrm{KCl}$ ) control solutions of VFA and glucose treatments were infused at the same vol, $\mathrm{pH}$ and osmolarity (respectively 50 and $10 \mathrm{l} / \mathrm{d}$, 2.8 and 7,340 and $700 \cdot \operatorname{mosm} / \mathrm{l}$ ) as the associated energy infusion. A mixed pelleted ration (0.97 UFL/kg DM) was offered ad libitum once daily.

The VFA infusion depressed food intake in lactating cows (mainly at time 2 to 3 and 8 to $12 \mathrm{~h}$ after the ration was offered), but had hardly any effect on dry cows. The satiety effect of VFA was higher during the first week than the second $(-3.7$ vs $-1.5 \mathrm{~kg} \mathrm{DM} / \mathrm{d}$ for lactating cows). In both lactating and dry cows, VFA infusion was associated with an increase in the turnover rate of fluid in the reticulo-rumen, a lower osmolarity and no effect on $\mathrm{pH}$. The glucose infusion did not significantly affect the amount of food intake of lactating and dry cows (respectively -0.7 and $+0.3 \mathrm{~kg}$ of $\mathrm{DM} / \mathrm{d}, P>0.1$ ).

In conclusion, it seems that: 1) the short-term control of food intake is more sensitive to the type of nutrients than to their energetic value; 2 ) the dry cows are unexpectedly less sensitive to the satiety signal of VFA than the lactating cows in spite of a more positive energy balance.

Faverdin P (1990) Reprod Nutr Dev suppl 2, $213 s-214 s$

Table I. Effect of volatile fatty acids infusion in the rumen.

\begin{tabular}{lccccc}
\hline & \multicolumn{2}{c}{ Lactating cows } & & \multicolumn{2}{c}{ Dry cows } \\
\cline { 2 - 3 } & Control & VFA & & Control & VFA \\
\hline Intake $(\mathrm{kg}$ DM/d) & 20.9 & $-2.6^{* *}$ & & 13.6 & -0.8 \\
Rumen pH & 6.2 & +0.1 & & 6.3 & -0.1 \\
Rumen osmolarity (mosm/l) & 304 & $-10^{*}$ & & 325 & $-15^{*}$ \\
Rumen turnover rate of fluid $(\% / \mathrm{h})$ & 11.7 & $+2.2^{*}$ & & 14.2 & $+1.7^{*}$ \\
\hline
\end{tabular}

Within a group of cows: $* P<0.05, \cdots P<0.01$. 